\title{
Associations between Cognition and Hand Function in Older People Diagnosed with Mild Cognitive Impairment or Dementia
}

\author{
Karin Hesseberg ${ }^{a, b} \quad$ Gro Gujord Tangen ${ }^{c-e} \quad$ Are Hugo Pripp ${ }^{f}$ \\ Astrid Bergland ${ }^{b}$ \\ aDivision of Medical Services, Diakonhjemmet Hospital, Oslo, Norway; ${ }^{b}$ Division of \\ Physiotherapy, Faculty of Health Sciences, OsloMet, Oslo Metropolitan University, Oslo, \\ Norway; ${ }^{c}$ Norwegian National Advisory Unit on Ageing and Health, Vestfold Hospital Trust, \\ Tønsberg, Norway; ${ }^{\mathrm{d}}$ Department of Geriatric Medicine, Oslo University Hospital, Oslo,

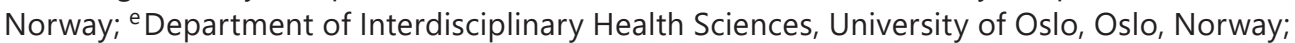 \\ ${ }^{\mathrm{f} F a c u l t y}$ of Health Sciences, OsloMet, Oslo Metropolitan University, Oslo, Norway
}

\section{Keywords}

Hand function · Cognitive functioning · Mild cognitive impairment · Dementia - Older people

\section{Abstract}

Background/Aims: The aim of this study was to examine the associations between different cognitive domains and hand function in older people diagnosed with mild cognitive impairment $(\mathrm{MCl})$ or dementia. Methods: This study is cross-sectional, including 98 communityliving older people aged $\geq 65$ years with $\mathrm{MCl}$ or dementia. Assessments of hand function included grip strength, the Finger Tapping Test, and the Grooved Pegboard. Cognitive assessments were the Mini-Mental State Examination, the Clock Drawing Test, and Trail Making Tests A and B, as well as a 10-word List Learning Test. Statistical analyses were based on descriptive statistics and univariable and multivariable analyses. Results: Sixty participants were diagnosed with $\mathrm{MCl}$ and 38 were diagnosed with dementia. The mean age was 78.8 years (SD 7.4). Analyses of hand function, cognitive tests, and demographic factors showed an association between cognitive tests, in particular executive function (EF), and hand function. Conclusions: The findings indicated an association between physical and cognitive function. Among the cognitive domains, declines in EF were most related to a reduced physical function. 


\section{Introduction}

Smaller differences in dependency in older people are associated with large differences in the cost of care, the need for informal care, and wellbeing [1, 2]. Cognitive impairments, including dementia, are a major cause of disability and dependency [3], and the risk of a poor health-related quality of life is greater in individuals with both physical and cognitive problems $[4,5]$. Cognitive impairment and difficulties with mobility often coexist, and current evidence suggests a shared underlying pathophysiology $[6,7]$. Converging evidence points to the important role of multiple cognitive domains, especially attention and executive function (EF), in explaining the high variability in physical function in healthy, frail, and older people with dementia [8]. A common feature of the descriptions of EF is that executive processes are part of a system that acts in a supervisory capacity in the overall hierarchy of brain processing and encompasses the skills necessary for purposeful goal-directed behavior $[9,10]$.

Studies show a consistent association between cognitive function and different aspects of physical function such as gait speed, mobility, balance, and muscle strength [11-14]. However, other aspects of physical function, such as hand function, are less explored in persons with cognitive impairment and dementia [15]. Hand function can be assessed using outcomes targeting strength, speed, and dexterity. Loss of grip strength is a well-recognized feature of age-related decline in muscle strength, and it may be used as an overall health indicator in older adults [16]. A low grip strength has been shown to be a strong predictor of functional decline, length of hospital stay, morbidity, and mortality [17-19]. Furthermore, a weaker grip strength is related to a worse baseline performance in processing speed and EF [20], and several studies have found that a low grip strength is associated with dementia as well [21, 22] and is a feasible prognostic tool in clinical assessment [23].

When it comes to associations between hand motor function, dementia, and cognitive function, the research literature is sparse. Compared to healthy older adults, patients with mild cognitive impairment (MCI) and Alzheimer disease (AD) produced fewer finger taps and more variability in a finger tapping task [24]. Further, the variability in finger tapping was also negatively associated with severity of cognitive impairment, indicating a loss of fluency and speed in fine motor movements. Fritz et al. [25] demonstrated that hand motor function was differentiated between subtypes of dementia in a study where patients with AD had worse dexterity than patients with Parkinson disease with dementia but better dexterity than patients with dementia with Lewy bodies. Manual dexterity was associated with autonomy in self-care activities of daily living in a cross-sectional study of patients with MCI and AD [26]. These studies indicate an association between the degree of cognitive impairment and hand function; however, there is a lack of studies investigating the aspects of cognitive function that underlie this association with hand function. Self-reported upper extremity function was associated with cognitive impairment, and in particular with executive dysfunction, in a study of older primary-care patients with and without MCI [27]. A study by Rodríguez-Aranda et al. [28] noted significant associations between EF, working memory, and manual dexterity in cognitively healthy young and older adults. Another study reported that manual dexterity, but not grip strength, was associated with EF in cognitively healthy older people [29]. The associations of handgrip strength and hand dexterity with cognitive performance in community-dwelling older adults are summarized in a review article with the conclusion that these associations are still unclear and future studies are needed [15]. However, we have not found studies examining the association between hand function and cognition in older people with cognitive impairment.

This study aimed to examine which domains of cognitive function have the strongest association with hand function in older people diagnosed with MCI or dementia.

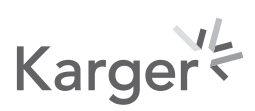




\section{Methods}

\section{Study Population and Design}

The inclusion criteria in this cross-sectional study were: community-living older people aged $\geq 65$ years, a diagnosis of MCI or dementia, and agreement to being included in the Norwegian register of persons assessed for cognitive symptoms (NorCog) [30]; subjects were recruited from 4 memory clinics in Norway. The diagnostic procedures for $\mathrm{MCI}$ and dementia are described in the below. Because this study was part of a longitudinal study with a 1-year follow-up, persons with an expected lifespan of $<1$ year due to terminal disease were excluded. All patients who fulfilled the inclusion criteria and were not excluded were asked to participate. In all, there were 98 participants. STROBE guidelines have been followed to report on the design, analysis, and presentation of data [31].

\section{Diagnostic Procedures}

Winblad criteria were used when diagnosing MCI [32] and the ICD-10 classification for research was used when diagnosing dementia [33]. Physicians at the memory clinics diagnosed the patients based on a standard comprehensive examination protocol that included taking a medical history and information from a family carer, a physical examination, testing of cognitive function, and a psychiatric evaluation with a primary emphasis on depression [34]. Magnetic resonance imaging (MRI) or a computerized tomography scan (CT) was performed as a structural brain examination on all patients. If the clinicians needed more information to make a correct diagnosis, a lumbar puncture with measurement of cerebrospinal fluid biomarkers was performed [34].

\section{Demographic Information}

Information on the diagnosis, age, gender, education, and marital status was retrieved from the NorCog.

\section{Assessment of Hand Function}

Grip strength was measured with a Jamar dynamometer [10]. The patients were seated with their elbows by their side and flexed to $90^{\circ}$, with their wrists in a neutral position. Both hands were tested, and the best results of 2 trials of the best hand were used in the analyses. Reference values and good reliability and validity in adults have been reported $[16,35,36]$. A reliability coefficient above 0.70 is shown in normal persons and persons with neurological damage [10].

The Finger Tapping Test measures psychomotor speed and is part of the Halstead-Reitan [37] Neuropsychological Test Battery. The test is generally used to evaluate persons with a suspected brain injury, but it also provides useful information about the cause of brain injury, i.e., AD [37]. The test is able to distinguish between normal control persons and people with a traumatic brain injury and it can also show the severity of a brain injury [10]. This testifies to its strong validity. The procedure as described by Reitan and Wolfson [38] provides reliable results. The Finger Tapping Test is performed by pressing the index finger on the dominant hand as quickly as possible for $10 \mathrm{~s}$ on a counting machine. The mean of 5 trials is reported and was used for analyses, but if the variation in the number of taps was over 5 taps during the 5 trials, the mean of 10 trials was used as a result [37].

The Grooved Pegboard test measures manual dexterity, visuo-motor coordination, and motor speed, and it shows good test-retest reliability [10]. The test material consists of 25 holes with randomly positioned grooves so that the pins must be rotated properly to match the hole into which they should be placed. The outcome is the time required to place the pegs, and a trial was discontinued after $5 \mathrm{~min}$ and the result was set to $300 \mathrm{~s}$ [39]. The test was

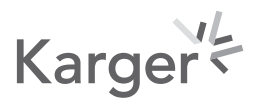


conducted with the dominant hand. Regarding validity, it should be noted that there may be more reasons than neurological damage, such as having reduced tactile sensation in their fingertips or reduced vision, for a person scoring badly on this task [10].

\section{Cognitive Assessments}

The results of the cognitive assessments were retrieved from the NorCog. The MiniMental State Examination (MMSE) was used to assess global cognition and it has a score range of $0-30$, where higher scores indicate a better performance [40]. The Clock Drawing Test (CDT) evaluates cognitive skills such as visual-spatial abilities and EF. A 6-point score from 0-5 was used, and test scores of 4-5 indicate a normal score according to the scoring procedure of Shulman $[10,41]$. Trail Making Tests A and B (TMTA and TMTB) were used to test attention and processing speed and to test EF and set shift, respectively [38]. The tests are timed in seconds [42]. When the patient could not complete the test, the score was set to $180 \mathrm{~s}$ for the TMTA and to $360 \mathrm{~s}$ for TMTB. The 10 -word List Learning Test from the Consortium to Establish a Registry for Alzheimer's Disease (CERAD) was used to evaluate the learning aspect of memory. A list of 10 words was presented 3 times, and scoring of 0-30 was used to measure the total number of correct words learned (10-word recall) [43]. Testing was conducted by experienced nurses, occupational therapists, and physicians at the memory clinics.

\section{Statistical Analysis}

Continuous variables are described as means (SD) and categorical variables are presented as numbers of observations (\%). To assess the differences between patients diagnosed with MCI and dementia, we used the $\chi^{2}$ test for categorical data or an independent samples $t$ test for continuous data. Multivariable linear regression models were used to assess associations between physical function and cognitive performance. Dependent variables included the hand function assessments. Independent variables included the cognitive tests MMSE, CDT, TMTA, and TMTB and the 10-word List Learning Test, as well as the demographic factors age, gender, education, and marital status. To identify the cognitive domains most related to the components of physical function, we used a stepwise regression analysis with the criterion of a $p$ value $<0.15$ to be included in the final model. Bivariate correlations and analysis of multicollinearity were preformed to detect any high levels of association between the independent variables. Residual plots were inspected. $p<0.05$ was considered statistically significant. Statistical analyses were performed using SPSS for Windows version 25.0.

\section{Results}

In total, 98 participants ( 45 men and 53 women) were included. Of those included, 60 were diagnosed with MCI and 38 were diagnosed with dementia. The mean age was 78.8 years, the mean years of education was 13.5 , and $40 \%$ were living alone. Characteristics of the participants and differences between participants with MCI and those with dementia are shown in Table 1. There were no significant differences in demographic characteristics between participants with MCI and those with dementia, and we did not observe any differences in hand function between those 2 groups, apart from performance on the Grooved Pegboard. Table 2 shows results from a linear regression analysis on the relationship between the hand function variables with cognitive tests and demographic factors (age, gender, marital status, and education). Our results showed that finger tapping was significant associated with the cognitive tests and domains representing visual-spatial abilities, set shift, and EF (measured by CDT and TMTB); grip strength was significant associated with the cognitive tests and domains representing EF and set shift (measured by TMTB) and the Grooved 
Table 1. Characteristics of the participants

\begin{tabular}{|c|c|c|c|c|c|c|c|c|}
\hline \multirow[t]{2}{*}{ Variable } & \multirow[t]{2}{*}{$n$} & \multicolumn{2}{|l|}{ All } & \multicolumn{2}{|l|}{$\mathrm{MCI}$} & \multicolumn{2}{|l|}{ Dementia } & \multirow[t]{2}{*}{$p$ value } \\
\hline & & mean (SD) & $\%$ & mean (SD) & $\%$ & mean (SD) & $\%$ & \\
\hline \multicolumn{9}{|l|}{ Demographics } \\
\hline Female & 98 & & 54 & & 52 & & 58 & $0.547^{\mathrm{a}}$ \\
\hline Diagnosis (MCI or dementia, \% MCI) & 98 & & 61 & & & & & \\
\hline Living alone & 98 & & 40 & & 37 & & 45 & $0.426^{\mathrm{a}}$ \\
\hline Age, years & 98 & $78.8(7.4)$ & & $77.9(7.2)$ & & $80.1(7.6)$ & & $0.151^{\mathrm{b}}$ \\
\hline Education, years & 82 & $13.5(3.3)$ & & $14.0(3.3)$ & & $12.6(3.1)$ & & $0.052^{\mathrm{b}}$ \\
\hline \multicolumn{9}{|l|}{ Cognitive assessment } \\
\hline MMSE (score 0-30) & 98 & $24.1(3.9)$ & & $25.5(2.9)$ & & $21.8(4.3)$ & & $<0.001^{\mathrm{b}}$ \\
\hline Ten-word recall (score 0-30) & 95 & $12.3(4.5)$ & & $13.4(4.3)$ & & $10.6(4.4)$ & & $0.003^{\mathrm{b}}$ \\
\hline CDT (\% normal, score 4-5) & 98 & & 51 & & 60 & & 37 & $0.025^{\mathrm{a}}$ \\
\hline TMTA, s & 98 & $86(41.8)$ & & 77 (35.8) & & $100(47.0)$ & & $0.012^{\mathrm{b}}$ \\
\hline TMTB, s & 97 & $276(102.6)$ & & 248 (107.3) & & $321(76.0)$ & & $<0.001^{\mathrm{b}}$ \\
\hline \multicolumn{9}{|l|}{ Hand function } \\
\hline Grip strength, kg & 97 & $25.5(10.8)$ & & $26.2(11.5)$ & & $24.4(9.8)$ & & $0.425^{\mathrm{b}}$ \\
\hline Grooved Pegboard time, s & 97 & $157(72.0)$ & & $144(63.0)$ & & $177(80.8)$ & & $0.034^{\mathrm{b}}$ \\
\hline Finger tapping, $n$ & 97 & $33.8(11.3)$ & & $35(11.4)$ & & $32(11.1)$ & & $0.206^{\mathrm{b}}$ \\
\hline
\end{tabular}

Pegboard was significant associated with the cognitive tests and domains representing EF and set-shift, attention, and processing speed (measured by TMTB and TMTA). Our model explained $64 \%$ of the variance in grip strength, $40 \%$ of the variance in the Grooved Pegboard, and $43 \%$ of the variance in finger tapping (Table 2).

\section{Discussion}

The findings of this study add information to the sparse body of research on the association between cognitive function and hand function. The correlation between physical and cognitive impairments has been of great interest to researchers and healthcare providers as it may facilitate early identification of individuals at the highest risk for dementia and it may generate tailored interventions to best preserve cognitive function [44]. The importance of hand function in everyday life is enabling independence. Most basic as well as complex activities of daily living, such as feeding, grooming, handling finances, and taking medication, become difficult without a normal hand function and often lead the individual to be reliant on caregiver assistance. Furthermore, fine hand function is essential for object manipulation [45]. Many etiological subtypes of dementia have demonstrated motor impairment as the disease progresses [12]. Converging evidence points to the important role of multiple cognitive domains, especially attention and EF, in explaining the high variability in mobility performance in healthy and frail older people and older people with dementia [8]. In our study, we found associations between hand function, assessed with grip strength, finger tapping, and the Grooved Pegboard, and cognitive domains such as EF, attention, set shift, visual-spatial abilities, and processing speed in older people with $\mathrm{MCI}$ or dementia. This supports our earlier findings regarding associations between physical fitness (components of the Senior Fitness Test) and cognition, where the cognitive domains attention and EF were most related to measured physical function [14]. Our results are in line with previous research from one population-based study with 2,160 participants with a MMSE score $>21$ [21] and 
Table 2. Associations between hand function items and cognitive assessments

\begin{tabular}{|c|c|c|c|c|c|c|c|c|}
\hline & \multicolumn{4}{|c|}{ Univariable linear regression analysis } & \multicolumn{4}{|c|}{ Stepwise regression analysis } \\
\hline & $B$ & $95 \% \mathrm{CI}$ & $p$ value & $\begin{array}{l}\text { adjusted } \\
R^{2}\end{array}$ & $B$ & $95 \% \mathrm{CI}$ & $p$ value & $\begin{array}{l}\text { adjusted } \\
R^{2}\end{array}$ \\
\hline Grip strength $(\mathrm{kg})(n=97)$ & & & & & & & & 0.644 \\
\hline Education (years) & 0.83 & 0.14 to 1.51 & 0.019 & 0.056 & & & & \\
\hline Age (years) & -0.66 & -0.92 to -0.39 & $<0.001$ & 0.196 & -0.42 & -0.62 to -0.21 & $<0.001$ & \\
\hline If female & -15.46 & -18.54 to -12.36 & $<0.001$ & 0.507 & -13.32 & -16.08 to -10.57 & $<0.001$ & \\
\hline If living alone & -9.14 & -13.21 to -5.07 & $<0.001$ & 0.164 & & & & \\
\hline MMSE & 0.24 & -0.33 to 0.80 & 0.407 & 0.003 & & & & \\
\hline 10-word list recall & 0.32 & -0.17 to 0.82 & 0.197 & 0.007 & & & & \\
\hline CDT (if normal) & 8.04 & 3.97 to 12.12 & $<0.001$ & 0.130 & & & & \\
\hline TMTA (s) & -0.06 & -0.11 to -0.01 & 0.032 & 0.037 & & & & \\
\hline TMTB (s) & -0.03 & -0.05 to -0.01 & 0.016 & 0.050 & -0.02 & -0.04 to -0.01 & 0.001 & \\
\hline Grooved Pegboard (s) $(n=90$ & & & & & & & & 0.402 \\
\hline Education (years) & 2.03 & -6.69 to 2.63 & 0.388 & -0.003 & & & & \\
\hline Age (years) & 2.65 & 0.76 to 4.56 & 0.007 & 0.065 & 1.69 & 0.16 to 3.22 & 0.031 & \\
\hline If female & 19.84 & -9.20 to 48.87 & 0.178 & 0.009 & & & & \\
\hline If living alone & 12.04 & -17.63 to 41.71 & 0.422 & -0.004 & & & & \\
\hline MMSE & -4.34 & -8.01 to -0.68 & 0.021 & 0.045 & & & & \\
\hline 10-word list recall & -0.77 & -4.05 to 2.51 & 0.642 & -0.008 & & & & \\
\hline CDT (if normal) & -62.17 & -88.47 to -35.87 & $<0.001$ & 0.180 & & & & \\
\hline TMTA (s) & 1.04 & 0.75 to 1.32 & $<0.001$ & 0.352 & 0.76 & 0.46 to 1.08 & $<0.001$ & \\
\hline TMTB (s) & 0.34 & 0.22 to 0.47 & $<0.001$ & 0.236 & 0.17 & 0.04 to 0.30 & 0.010 & \\
\hline Finger tapping $(n)(n=97)$ & & & & & & & & 0.429 \\
\hline Education (years) & 0.86 & 0.12 to 1.60 & 0.024 & 0.051 & & & & \\
\hline Age (years) & -0.29 & -0.60 to 0.01 & 0.059 & 0.027 & & & & \\
\hline If female & -11.88 & -15.78 to -7.98 & $<0.001$ & 0.270 & -10.09 & -13.98 to -6.20 & $<0.001$ & \\
\hline If living alone & -5.82 & -10.33 to -1.31 & 0.012 & 0.055 & & & & \\
\hline MMSE & 0.24 & -0.35 to 0.82 & 0.428 & -0.004 & & & & \\
\hline 10 -word list recall & 0.11 & -0.40 to 0.62 & 0.675 & -0.009 & & & & \\
\hline CDT (if normal) & 9.58 & 5.45 to 13.72 & $<0.001$ & 0.174 & 5.46 & 0.81 to 10.12 & 0.022 & \\
\hline TMTA (s) & -0.09 & -0.14 to -0.04 & 0.001 & 0.105 & & & & \\
\hline TMTB (s) & -0.03 & -0.05 to -0.01 & 0.007 & 0.065 & -0.03 & -0.05 to -0.01 & 0.018 & \\
\hline
\end{tabular}

$B$, unstandardized coefficient.

another population-based study with 4,000 community-dwelling participants aged 65 years or older [46]. These studies found that grip strength was associated with cognitive function $[21,46]$. Furthermore, prospective studies of 1,793 older women participating in the Women's Health Initiative Memory Study [47] and 3,522 participants of the Honolulu Heart Program and the Honolulu-Asia Aging Study [48] indicate that cognition predicts grip strength [47,48]. Hooghiemstra et al. [20] reported that a weaker grip strength was significantly related to a worse baseline performance in processing speed and EF, as in our study. However, their findings showed that there were no longitudinal associations and they suggested in their conclusion that markers of physical performance are related to current cognitive status and modestly related to cognitive decline but they are seemingly not useful as an early marker of incidental clinical progression [20].

A recent population-based longitudinal study of 1,243 Italian adults aged 65 years or older aimed to investigate whether a reduced function in fine motor skills measured by pegboard and how well the participants managed to put on and button up a shirt correctly as quickly as possible were predictors of cognitive impairment [49]. Curreri et al. [49] reported 
significant associations between difficulties in fine motor skills and cognitive performance, which corresponds well with our results. In our study, the tests of fine motor skills were associated with the cognitive tests representing EF, attention, and processing speed. Assessments of fine motor skills may help to identify early signs of dementia, as well as subjects at a high risk of developing cognitive decline, and individuals who can be referred to specialists. The results will add information for physiotherapists and other health personnel regarding how they can better contribute to tailoring their interventions and assessments in their professional practice for older people with MCI or dementia. It is also important to acknowledge the association between impaired hand function and cognition for those who develop technological assistive devices aimed at persons with cognitive impairment and dementia.

\section{Limitations}

The cross-sectional design of this study is a limitation that prevents us from drawing conclusions about causality [50]. Potential factors that could influence the association between hand function and cognitive functions other than those assessed in our study, such as depression and other diseases, could be investigated. Furthermore, not all cognitive domains have been examined, and thus there could be associations between hand function and cognition other than those reported in this study. The sample comprised participants referred to memory clinics and thus did not represent a broad selection of patients with MCI and dementia. This means that our results cannot be generalized to apply to all patients with MCI or dementia. A larger sample size could have strengthened this study as well. As the authors of a recent systematic review synthesizing the existing observational studies evaluating the associations of hand function with cognitive performance in community-dwelling older adults, we agree that longitudinal studies are needed to elucidate this association [15].

\section{Conclusion}

The findings above suggest that impairments in EF are most associated with a reduced hand function. These patients should receive special attention, as they might have a higher risk of losing independence because hand function is important in order to carry out many daily activities. Our results strengthen the need to focus on other factors more amenable than medication to increasing the possibility for maintenance of independent living in this patient group.

\section{Acknowledgement}

The authors thank all of the participants for volunteering to participate in this study.

\section{Statement of Ethics}

This study was approved by the Regional Committee for Medical Research Ethics in South-Eastern Norway (2010/2673). The participants were given oral and written information about this study and signed a written informed consent form. Before the participants were included in this study, a physician at the memory clinic assessed whether the participants were able to give their consent. Our population consisted of older people with MCI and early dementia, and at these stages of disease consent is less problematic than with more severe dementia. The participants were followed closely during the assessments, and they

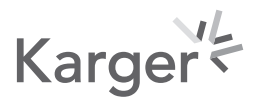


were asked if they needed breaks. They were also instructed that they could withdraw from further testing and from the entire study at any time. No adverse events were recorded.

\section{Conflict of Interest Statement}

The authors have no conflict of interests to declare.

\section{Funding Sources}

Funding was obtained as part of the employment of the authors (Diakonhjemmet Hospital, OsloMet - Oslo Metropolitan University and Norwegian National Advisory Unit on Ageing and Health).

\section{Author Contributions}

K.H. performed the data collection, testing of the participants, and analysis of the data. K.H. and A.B. contributed to conception and design of the study and drafted parts of this paper. All of the authors discussed the analysis of the data and the results and read and approved the final version of this paper.

\section{References}

1 World Health Organization, Alzheimer's Disease International. Dementia: a public health priority. 2012. Available from: http://www.who.int/mental_health/publications/dementia_report_2012/en/.

2 Zhu N, Jacobs DR Jr, Schreiner PJ, Yaffe K, Bryan N, Launer LJ, et al. Cardiorespiratory fitness and cognitive function in middle age: the CARDIA study. Neurology. 2014 Apr;82(15):1339-46.

3 World Health Organization. Dementia: fact sheet. Geneva: WHO; 2017.

4 Inouye SK, Studenski S, Tinetti ME, Kuchel GA. Geriatric syndromes: clinical, research, and policy implications of a core geriatric concept. J Am Geriatr Soc. 2007 May;55(5):780-91.

5 Taş U, Verhagen AP, Bierma-Zeinstra SM, Hofman A, Odding E, Pols HA, et al. Incidence and risk factors of disability in the elderly: the Rotterdam Study. Prev Med. 2007 Mar;44(3):272-8.

6 Cotman CW, Berchtold NC, Christie LA. Exercise builds brain health: key roles of growth factor cascades and inflammation. Trends Neurosci. 2007 Sep;30(9):464-72.

7 Giovannini S, Onder G, Liperoti R, Russo A, Carter C, Capoluongo E, et al. Interleukin-6, C-reactive protein, and tumor necrosis factor-alpha as predictors of mortality in frail, community-living elderly individuals. J Am Geriatr Soc. 2011 Sep;59(9):1679-85.

8 Holtzer R, Wang C, Verghese J. Performance variance on walking while talking tasks: theory, findings, and clinical implications. Age (Dordr). 2014 Feb;36(1):373-81.

9 Alvarez JA, Emory E. Executive function and the frontal lobes: a meta-analytic review. Neuropsychol Rev. 2006 Mar;16(1):17-42.

10 Strauss E, Sherman EM, Spreen O. A compendium of neuropsychological tests: administration, norms, and commentary. Oxford: Oxford University Press; 2006. 1216 pp.

11 McGough EL, Kelly VE, Logsdon RG, McCurry SM, Cochrane BB, Engel JM, et al. Associations between physical performance and executive function in older adults with mild cognitive impairment: gait speed and the timed "up \& go" test. Phys Ther. 2011 Aug;91(8):1198-207.

12 Stuck AE, Walthert JM, Nikolaus T, Büla CJ, Hohmann C, Beck JC. Risk factors for functional status decline in community-living elderly people: a systematic literature review. Soc Sci Med. 1999 Feb;48(4):445-69.

13 Tangen GG, Engedal K, Bergland A, Moger TA, Mengshoel AM. Relationships between balance and cognition in patients with subjective cognitive impairment, mild cognitive impairment, and Alzheimer disease. Phys Ther. 2014 Aug;94(8):1123-34.

14 Hesseberg K, Bentzen H, Ranhoff AH, Engedal K, Bergland A. Physical Fitness in Older People with Mild Cognitive Impairment and Dementia. J Aging Phys Act. 2016 Jan;24(1):92-100. 
15 Kobayashi-Cuya KE, Sakurai R, Suzuki H, Ogawa S, Takebayashi T, Fujiwara Y. Observational Evidence of the Association Between Handgrip Strength, Hand Dexterity, and Cognitive Performance in Community-Dwelling Older Adults: A Systematic Review. J Epidemiol. 2018 Sep;28(9):373-81.

16 Bohannon RW. Test-Retest Reliability of Measurements of Hand-Grip Strength Obtained by Dynamometry from Older Adults: A Systematic Review of Research in the PubMed Database. J Frailty Aging. 2017;6(2):83-7.

17 Bohannon RW. Muscle strength: clinical and prognostic value of hand-grip dynamometry. Curr Opin Clin Nutr Metab Care. 2015 Sep;18(5):465-70.

18 Syddall H, Cooper C, Martin F, Briggs R, Aihie Sayer A. Is grip strength a useful single marker of frailty? Age Ageing. 2003 Nov;32(6):650-6.

19 Turusheva A, Frolova E, Degryse JM. Age-related normative values for handgrip strength and grip strength's usefulness as a predictor of mortality and both cognitive and physical decline in older adults in northwest Russia. J Musculoskelet Neuronal Interact. 2017 Mar;17(1):417-32.

20 Hooghiemstra AM, Ramakers IH, Sistermans N, Pijnenburg YA, Aalten P, Hamel RE, et al.; 4C Study Group. Gait Speed and Grip Strength Reflect Cognitive Impairment and Are Modestly Related to Incident Cognitive Decline in Memory Clinic Patients With Subjective Cognitive Decline and Mild Cognitive Impairment: Findings From the 4C Study. J Gerontol A Biol Sci Med Sci. 2017 Jun;72(6):846-54.

21 Alfaro-Acha A, Al Snih S, Raji MA, Kuo YF, Markides KS, Ottenbacher KJ. Handgrip strength and cognitive decline in older Mexican Americans. J Gerontol A Biol Sci Med Sci. 2006 Aug;61(8):859-65.

22 Buchman AS, Wilson RS, Boyle PA, Bienias JL, Bennett DA. Grip strength and the risk of incident Alzheimer's disease. Neuroepidemiology. 2007;29(1-2):66-73.

23 Sayer AA, Kirkwood TB. Grip strength and mortality: a biomarker of ageing? Lancet. 2015 Jul;386(9990):226-7.

24 Roalf DR, Rupert P, Mechanic-Hamilton D, Brennan L, Duda JE, Weintraub D, et al. Quantitative assessment of finger tapping characteristics in mild cognitive impairment, Alzheimer's disease, and Parkinson's disease. J Neurol. 2018 Jun;265(6):1365-75.

25 Fritz NE, Kegelmeyer DA, Kloos AD, Linder S, Park A, Kataki M, et al. Motor performance differentiates individuals with Lewy body dementia, Parkinson's and Alzheimer's disease. Gait Posture. 2016 0ct;50:1-7.

26 de Paula JJ, Albuquerque MR, Lage GM, Bicalho MA, Romano-Silva MA, Malloy-Diniz LF. Impairment of fine motor dexterity in mild cognitive impairment and Alzheimer's disease dementia: association with activities of daily living. Br J Psychiatry. 2016 Jul-Sep;38(3):235-8.

27 Rycroft SS, Quach LT, Ward RE, Pedersen MM, Grande L, Bean JF. The Relationship Between Cognitive Impairment and Upper Extremity Function in Older Primary Care Patients. J Gerontol A Biol Sci Med Sci. 2019 Mar; 74(4):568-74.

28 Rodríguez-Aranda C, Mittner M, Vasylenko O. Association Between Executive Functions, Working Memory, and Manual Dexterity in Young and Healthy Older Adults: An Exploratory Study. Percept Mot Skills. 2016 Feb; 122(1):165-92.

29 Kobayashi-Cuya KE, Sakurai R, Sakuma N, Suzuki H, Yasunaga M, Ogawa S, et al. Hand dexterity, not handgrip strength, is associated with executive function in Japanese community-dwelling older adults: a cross-sectional study. BMC Geriatr. 2018 Aug;18(1):192.

30 Aldring og helse. Norcog. Available from: https://www.aldringoghelse.no/norkog/.

31 von Elm E, Altman DG, Egger M, Pocock SJ, Gøtzsche PC, Vandenbroucke JP; STROBE Initiative. The Strengthening the Reporting of Observational Studies in Epidemiology (STROBE) Statement: guidelines for reporting observational studies. Int J Surg. 2014 Dec;12(12):1495-9.

32 Winblad B, Palmer K, Kivipelto M, Jelic V, Fratiglioni L, Wahlund LO, et al. Mild cognitive impairment-beyond controversies, towards a consensus: report of the International Working Group on Mild Cognitive Impairment. J Intern Med. 2004 Sep;256(3):240-6.

33 World Health Organization. The ICD-10 Classification of Mental and Behavioural Disorders: Clinical Descriptions and Diagnostic Guidelines. Royal College of Psychiatrists; 1992.

34 Brækhus A, Ulstein I, Wyller TB, Engedal K. The Memory Clinic-outpatient assessment when dementia is suspected. Tidsskr Nor Laegeforen. 2011 Nov;131(22):2254-7.

35 Bohannon RW, Peolsson A, Massy-Westropp N, Desrosiers J, Bear-Lehman J. Reference values for adult grip strength measured with a Jamar dynamometer: a descriptive meta-analysis. Physiotherapy. 2006;92(1):11-5.

36 Shechtman 0, Gestewitz L, Kimble C. Reliability and validity of the DynEx dynamometer. J Hand Ther. Jul-Sep 2005;18(3):339-47.

37 Halstead-Reitan battery. 2019. Available from: http://www.minddisorders.com/Flu-Inv/Halstead-ReitanBattery.html\#ixzz3DkfV3Rss.

38 Reitan RM, Wolfson D. The Halstead-Reitan Neuropsychological Test Battery: Theory and Clinical Interpretation. Neuropsychology Press; 1993.

39 Lafayette Instrument Company. Grooved Peg Board Test. 2019. Available from: http://lafayetteinstrumenteurope.com/product detail.asp?ItemID=167\&cat=106.

40 Folstein MF, Folstein SE, McHugh PR. "Mini-mental state”. A practical method for grading the cognitive state of patients for the clinician. J Psychiatr Res. 1975 Nov;12(3):189-98.

41 Shulman KI. Clock-drawing: is it the ideal cognitive screening test? Int J Geriatr Psychiatry. 2000 Jun;15(6): 548-61.

42 Ivnik RJ, Malec JF, Smith GE, Tangalos EG, Petersen RC. Neuropsychological tests' norms above age 55: COWAT, BNT, MAE token, WRAT-R reading, AMNART, STROOP, TMT, and JLO. Clin Neuropsychol. 1996;10(3):262-78. 


\section{Geriatric Cognitive Disorders Extra}

43 Fillenbaum GG, van Belle G, Morris JC, Mohs RC, Mirra SS, Davis PC, et al. Consortium to Establish a Registry for Alzheimer's Disease (CERAD): the first twenty years. Alzheimers Dement. 2008 Mar;4(2):96-109.

44 Verghese J, Annweiler C, Ayers E, Barzilai N, Beauchet O, Bennett DA, et al. Motoric cognitive risk syndrome: multicountry prevalence and dementia risk. Neurology. 2014 Aug;83(8):718-26.

45 Scherder E, Dekker W, Eggermont L. Higher-level hand motor function in aging and (preclinical) dementia: its relationship with (instrumental) activities of daily life-a mini-review. Gerontology. 2008;54(6):333-41.

46 Auyeung TW, Kwok T, Lee J, Leung PC, Leung J, Woo J. Functional decline in cognitive impairment-the relationship between physical and cognitive function. Neuroepidemiology. 2008;31(3):167-73.

47 Atkinson HH, Rapp SR, Williamson JD, Lovato J, Absher JR, Gass M, et al. The relationship between cognitive function and physical performance in older women: results from the women's health initiative memory study. J Gerontol A Biol Sci Med Sci. 2010 Mar;65(3):300-6.

48 Charles LE, Burchfiel CM, Fekedulegn D, Kashon ML, Ross GW, Sanderson WT, et al. Occupational and other risk factors for hand-grip strength: the Honolulu-Asia Aging Study. Occup Environ Med. 2006 Dec;63(12): 820-7.

49 Curreri C, Trevisan C, Carrer P, Facchini S, Giantin V, Maggi S, et al. Difficulties with Fine Motor Skills and Cognitive Impairment in an Elderly Population: The Progetto Veneto Anziani. J Am Geriatr Soc. 2018 Feb; 66(2):350-6.

50 Bangdiwala SI. Basic epidemiology research designs I: cross-sectional design. Int J Inj Contr Saf Promot. 2019 Mar;26(1):124-6. 